\title{
Optimization of the Reaction Conditions for the Synthesis of Dihydrobenzofuran Neolignans
}

\author{
Herbert J. Dias, ${ }^{\oplus \#, a}$ Matheus L. Rodrigues ${ }^{\oplus \#, a}$ and Antônio E. M. Crotti ${ }^{\oplus *, a}$ \\ ${ }^{a}$ Departamento de Química, Faculdade de Filosofia, Ciências e Letras de Ribeirão Preto, \\ Universidade de São Paulo, Av. Bandeirantes, 3900, Monte Alegre, \\ 14040-901 Ribeirão Preto-SP, Brazil
}

\begin{abstract}
We have optimized the experimental conditions for the silver(I)-promoted oxidative coupling of methyl $p$-coumarate (I) and methyl ferulate (II), which is the most frequently used methodology to synthesize the bioactive dihydrobenzofuran neolignans $1(( \pm)$-trans-dehydrodicoumarate dimethyl ester) and $2(( \pm)$-trans-dehydrodiferulate dimethyl ester). Most of the tested conditions affected the conversion (i.e., the consumption of I and II) and the selectivity (i.e., the percentage of I and II that was converted into $\mathbf{1}$ and $\mathbf{2}$, respectively), so the optimized conditions were the ones that afforded the best balance between conversion and selectivity. Silver(I) oxide ( 0.5 equiv.) is the most efficient oxidant agent amongst the silver(I) reagents that were tested to convert methyl esters I and II into compounds $\mathbf{1}$ and $\mathbf{2}$, respectively. Acetonitrile, which has not yet been reported as a solvent for this reaction, provided the best balance between conversion and selectivity, besides being "greener" than other solvents that are more often employed (e.g., dichloromethane and benzene). Under the optimized conditions, the reaction time decreased from 20 to $4 \mathrm{~h}$ without significantly impacting the conversion and selectivity.
\end{abstract}

Keywords: benzofuran derivatives, oxidative coupling, phenylpropanoids, radical intermediates

\section{Introduction}

Dihydrobenzofuran neolignans (DBNs) are compounds that are biosynthesized by plants as part of their secondary metabolism. DBNs result from oxidative coupling of two propenylphenols $\left(\mathrm{C}_{6} \mathrm{C}_{3}\right)$, which are joined through $\mathrm{C} 8-\mathrm{C} 5$, and $\mathrm{C} 7-\mathrm{O} 4$ ' bonds. ${ }^{1,2}$ Natural and synthetic DBNs exhibit diverse biological activities, such as anti-inflammatory, ${ }^{3}$ antioxidant, ${ }^{3}$ cytotoxic, ${ }^{4}$ schistosomicidal, ${ }^{5}$ leishmanicidal, ${ }^{6}$ and insecticidal actions, ${ }^{7}$ among others.

Despite the various synthetic methodologies that have been reported in the literature for the synthesis of DBNs (e.g., intramolecular C-H insertion ${ }^{8}$ and sequential cross-metathesis/isomerization/allylboration), ${ }^{9}$ oxidative coupling of phenylpropanoids, which mimics DBN biosynthesis in plants and affords the dihydrobenzofuran skeleton in only one synthetic step under mild conditions, is still the most commonly used. ${ }^{2}$ Silver(I) oxide is the classic oxidant that is employed to promote this coupling. In the mechanism proposed in the literature ${ }^{10}$

*e-mail: millercrotti@ ffclrp.usp.br

\#These authors contributed equally to this work. for the silver(I)-promoted oxidative coupling of phenylpropanoids, the first step consists of 4-OH bond homolysis, to generate the phenoxy radical intermediate B (Scheme 1). In preliminary studies, mass spectrometry has been used to track changes in the reaction mixture with time. These studies suggested that the phenoxy radical originates from oxidation of a phenolate anion A and consequent silver(I) reduction to silver(0), which precipitates in the reaction vessel internal walls (data not published) (Scheme 1). Next, a C5'-C8 bond is supposedly established between two phenoxy radical units, which is followed by ring closure (resulting from $\mathrm{O} 4-\mathrm{C} 7$ ' bond formation) and further tautomerization.

The silver(I) oxide-promoted oxidative coupling of phenylpropanoids is diastereoselective and gives DBNs as racemic mixtures of trans-enantiomers in $20-40 \%$ yield. ${ }^{10,11}$ Many efforts have been dedicated to replacing silver(I) oxide in this reaction to obtain DBN in higher stereoselectivity and yields. To this end, iron salts, ${ }^{12} \mathrm{Ru}$ and $\mathrm{Rh}$ complexes, ${ }^{13}$ the horseradish peroxidase (HRP) $/ \mathrm{H}_{2} \mathrm{O}_{2}$ system, ${ }^{14}$ and laccases have been employed.$^{15}$ However, stereoselectivity obtained for other metals than silver(I) in the oxidative coupling of phenylpropanoids to give DBNs 
<smiles>[R]C/C=C/c1ccc(OC)c([R])c1</smiles><smiles>[R]CC/C=C/c1cc([2H])c2c(c1)[C@H](C[2H])[C@@H](c1ccc(O)c([2H])c1)O2</smiles>

Scheme 1. Mechanism proposed for the silver(I) oxide-promoted oxidative coupling of phenylpropanoids to give dihydrobenzofuran neolignans (adapted from Daquino et al..). ${ }^{10}$

has not been clearly described..$^{12,13}$ On the other hand, some of these methods have provided good enantioselectivity (e.g., $\mathrm{HRP} / \mathrm{H}_{2} \mathrm{O}_{2}$ system and laccases) and increased yields. Nevertheless, the high cost or the experimental complexity ${ }^{8,9}$ as compared to the use of silver(I) oxide still makes the methodology based on silver(I) oxide more attractive.

In this paper, we have systematically investigated reaction conditions to optimize the silver(I)-promoted oxidative coupling of phenylpropanoids.

\section{Experimental}

\section{General}

The ${ }^{1} \mathrm{H}$ and ${ }^{13} \mathrm{C}$ nuclear magnetic resonance (NMR) analyses were performed on a Bruker Advance DRX400 spectrometer (Karlsruhe, Germany; $400.13 \mathrm{MHz}$ for ${ }^{1} \mathrm{H}$ and $100.61 \mathrm{MHz}$ for ${ }^{13} \mathrm{C}$ ), as described in the literature. ${ }^{11}$ The samples were dissolved in acetone- $d_{6}(99.8$ atom $\% \mathrm{D}$, Sigma-Aldrich, St. Louis, USA); tetramethylsilane (TMS, $0.01 \%$ ) was used as internal standard. The chemical shifts $(\delta)$ were expressed in parts per million (ppm) in relation to the residual solvent peak, and the multiplicity of signals was deduced according to the signals obtained in spectrum. The coupling constants $(\mathrm{J}$, in $\mathrm{Hz})$ were calculated in comparison to the same signal peaks, and the relative integral was deduced according to the number of hydrogens.
The infrared (IR) spectra were recorded on a spectrophotometer IR Spectrum Two (PerkinElmer, Beaconsfield, UK). The samples were macerated in potassium bromide $(99.99 \%$, Sigma-Aldrich, St. Louis, USA) and fused in a pellet under pressure.

The mass spectra were recorded on a gas chromatographmass spectrometer (GC-MS) Shimadzu QP2010-Plus (Kyoto, Japan) system equipped with an AOC-20i autosampler and an RTX-5MS (Restek Co., Bellefonte, PA, USA) fused silica capillary $(30 \mathrm{~m} \times 0.25 \mathrm{~mm}$ inner diameter, $0.25-\mu \mathrm{m}$ film thickness). The electron ionization mode was used at $70 \mathrm{eV}$. Helium (99.999\%) was employed as the carrier gas at a constant flow of $1.0 \mathrm{~mL} \mathrm{~min}$. The injection volume was $0.1 \mu \mathrm{L}$ (split ratio of $1: 10$ ). The injector and the ion-source temperatures were set at 280 and $300{ }^{\circ} \mathrm{C}$, respectively. The oven temperature was programmed to rise from 110 to $300{ }^{\circ} \mathrm{C}$ at $10{ }^{\circ} \mathrm{C} \mathrm{min}^{-1}$ and then held at $300{ }^{\circ} \mathrm{C}$ for $5 \mathrm{~min}$. The mass spectra were taken with a scan interval of $0.5 \mathrm{~s}$ for masses ranging from 40 to $600 \mathrm{Da}$.

\section{Synthesis of the dihydrobenzofuran neolignans $\mathbf{1}$ and $\mathbf{2}$}

The dihydrobenzofuran neolignans (DBNs) 1 and 2, which were used as standards, were synthesized by oxidative coupling of methyl p-coumarate (I) and methyl ferulate (II), respectively, in the presence of silver(I) oxide, as oxidant, as reported previously (Scheme 2). ${ }^{4,7,11,16}$

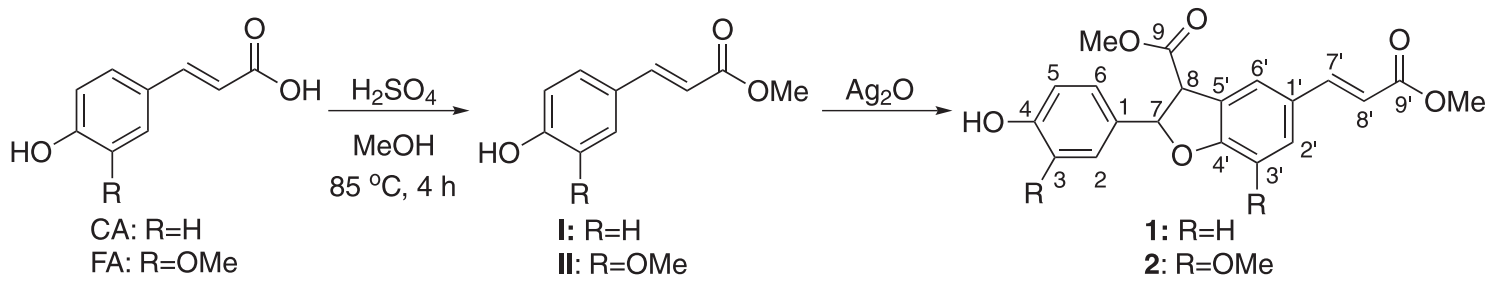

Scheme 2. Synthesis of the dihydrobenzofuran neolignans $\mathbf{1}$ and $\mathbf{2}$ by silver(I)-oxide oxidative coupling of methyl $p$-coumarate (I) and methyl ferulate (II), respectively (adapted from references 4,7,11,16). 
Methyl $p$-coumarate (I) was obtained from coumaric acid (CA, 3.0 g, $18.3 \mathrm{mmol}$ ) (Sigma-Aldrich, St. Louis, USA), which was dissolved in $30 \mathrm{~mL}$ of methanol in a 100-mL round-bottom flask, followed by addition of $1 \mathrm{~mL}$ of sulfuric acid. Methyl ferulate (II) was synthesized from ferulic acid (FA, $3.0 \mathrm{~g}, 15.4 \mathrm{mmol}$ ) (Sigma-Aldrich, St. Louis, USA), which was dissolved in $180 \mathrm{~mL}$ of methanol in a 500-mL round-bottom flask, followed by addition of $3 \mathrm{~mL}$ of sulfuric acid. The reaction mixtures were kept under reflux at $85^{\circ} \mathrm{C}$ for $4 \mathrm{~h}$. After methanol was removed under reduced pressure, the resulting crude products were dissolved in ethyl acetate and extracted with water and a saturated $\mathrm{NaHCO}_{3}$ solution $(3 \times 30 \mathrm{~mL})$. The organic phase was dried over $\mathrm{MgSO}_{4}$ and filtered. Ethyl acetate was removed from the samples under reduced pressure to afford compounds I and II as a yellowish powder and a brown powder in 94 and $95 \%$ yield, respectively.

Next, $3.0 \mathrm{~g}$ of methyl ester I (16.8 $\mathrm{mmol})$ or II (14.4 mmol) were added to a two-neck 100-mL roundbottom flask covered with aluminum foil and dissolved in $40 \mathrm{~mL}$ of a benzene/acetone (6:4) mixture under magnetic stirring and nitrogen atmosphere. Next, silver(I) oxide (8.5 mmol) (Sigma-Aldrich, St. Louis, USA) was added, and the reaction progress was monitored by thin layer chromatography (TLC) for $4 \mathrm{~h}$. The reaction mixture was filtered off, and the solvent was removed under reduced pressure. The crude products were purified by column chromatography as previously reported, ${ }^{11}$ to afford compounds 1 (35\% yield) and 2 (42\% yield) as mixtures of trans-enantiomers.

\section{Methyl $p$-coumarate (I)}

${ }^{1} \mathrm{H}$ NMR (400 MHz, $\left.\mathrm{CDCl}_{3}\right) \delta 7.65(\mathrm{~d}, J 16.1 \mathrm{~Hz}, 1 \mathrm{H}$, H-1'), 7.45 (d, J 8.6 Hz, 2H, H-2 and H-6), 6.85 (d, J 8.6 Hz, 2H, H-3 and H-5), 6.31 (d, J 16.1 Hz, 1H, H-2'), 5.03 (br s, 1H, OH), 3.80 (s, 3H, H-4'); EI-MS (70 eV, m/z, relative intensity /\%): $178\left[\mathrm{M}^{\circ+}\right](100), 147\left[\mathrm{M}^{\bullet+}-\bullet \mathrm{OCH}_{3}\right](90), 119$ $\left[\mathrm{M}^{\bullet+}-\bullet \mathrm{OCH}_{3}-\mathrm{CO}\right](90), 91\left[\mathrm{M}^{\bullet+}-\bullet \mathrm{OCH}_{3}-\mathrm{CO}-\mathrm{CO}\right]$ (25). The NMR data are in agreement with the literature. ${ }^{17}$

\section{Methyl ferulate (II)}

${ }^{1} \mathrm{H}$ NMR (400 MHz, $\left.\mathrm{CDCl}_{3}\right) \delta 7.63(\mathrm{~d}, J 16.0 \mathrm{~Hz}$, 1H, H-1'), 7.08 (dd, J 1.9, $8.1 \mathrm{~Hz}, 1 \mathrm{H}, \mathrm{H}-2), 7.04$ (d, $J 1.9 \mathrm{~Hz}, 1 \mathrm{H}, \mathrm{H}-6), 6.93$ (d, J $8.1 \mathrm{~Hz}, 1 \mathrm{H}, \mathrm{H}-3), 6.30$ (d, J $16.0 \mathrm{~Hz}, 1 \mathrm{H}, \mathrm{H}-2$ '), 5.89 (br s, 1H, OH), 3.93 (s, 3H, H-7), 3.80 (s, 3H, H-4'); EI-MS (70 eV, m/z, relative intensity / \%): $208\left[\mathrm{M}^{\circ+}\right](100), 177\left[\mathrm{M}^{*+}-\right.$ - $\left.\mathrm{OCH}_{3}\right](60), 145\left[\mathrm{M}^{\bullet+}-\bullet \mathrm{OCH}_{3}-\mathrm{CH}_{3} \mathrm{OH}\right](40), 117$ $\left[\mathrm{M}^{\cdot+}-\cdot \mathrm{OCH}_{3}-\mathrm{CH}_{3} \mathrm{OH}-\mathrm{CO}\right](22)$. The NMR data are in agreement with the literature. ${ }^{17}$
( \pm )-trans-Dehydrodicoumarate dimethyl ester (1)<smiles>COC(=O)/C=C/c1ccc2c(c1)[C@H](C(=O)OC)[C@H](c1ccc(O)cc1)O2</smiles>

Yellow powder; mp 105-107 ${ }^{\circ} \mathrm{C}$; IR ( $\mathrm{KBr}$ pellet) $v_{\max } / \mathrm{cm}^{-1} 3384(-\mathrm{OH}), 2955\left(\mathrm{C}_{\mathrm{sp} 2}-\mathrm{H}\right), 1715(\mathrm{C}=\mathrm{O})$, $1602(\mathrm{C}=\mathrm{C}), 1490$ ( $\mathrm{C}=\mathrm{C}), 1440(\mathrm{C}=\mathrm{C}), 1240(\mathrm{C}-\mathrm{O}), 1115$ $(\mathrm{C}-\mathrm{O}) ;{ }^{1} \mathrm{H}$ NMR $\left(400 \mathrm{MHz}\right.$, acetone- $\left.d_{6}\right) \delta 7.65(1 \mathrm{H}, \mathrm{d}$, $J$ 16.0, H7'), 7.62 (1H, br s, H6'), 7.50 (1H, dd, $J 1.5$ and $8.1 \mathrm{~Hz}, \mathrm{H} 2$ ') 7.28 (2H, dd, $J 1.8$ and $6.8 \mathrm{~Hz}, \mathrm{H} 2$ and H6), $6.91(1 \mathrm{H}, \mathrm{d}, J 8.1 \mathrm{~Hz}, \mathrm{H} 3$ '), 6.87 (2H, dd, $J 1.8$ and $6.8 \mathrm{~Hz}$, H5), 6.41 (1H, d, J 16.0 Hz, H8'), $6.03(1 \mathrm{H}, \mathrm{d}, J 7.3 \mathrm{~Hz}$, H7), 4.40 (1H, d, J7.3 Hz, H8), 3.81 (3H, s, H10), 3.73 (3H, s, H10'); ${ }^{13} \mathrm{C}$ NMR (100 MHz, acetone- $\left.d_{6}\right) \delta 172.0$ (C, C9), 168.2 (C, C9'), 162.6 (C, C4), 159.1 (C, C4'), 145.5 (CH, C7'), 132.1 (C, C1'), 131.3 (C, C1), 128.9 (CH, C2 and C6), 128.0 (CH, C2'), 126.9 (C), 126.5 (CH, C6'), 116.9 (CH, C3 and C5), 116.5 (CH, C8'), $111.2\left(\mathrm{CH}, \mathrm{C} 3{ }^{\prime}\right), 88.2(\mathrm{CH}$, C7), 56.0 ( $\mathrm{CH}, \mathrm{C} 8), 53.4\left(\mathrm{CH}_{3}, \mathrm{C} 10\right.$ '), $52.0\left(\mathrm{CH}_{3}, \mathrm{C} 10\right)$; EI-MS (70 eV, $m / z$, relative intensity / \%): $354\left[\mathrm{M}^{*+}\right](26)$, $322\left[\mathrm{M}^{\cdot+}-\mathrm{CH}_{3} \mathrm{OH}\right](30), 290\left[\mathrm{M}^{\bullet+}-\mathrm{CH}_{3} \mathrm{OH}-\mathrm{CH}_{3} \mathrm{OH}\right]$ (100). The NMR data are in agreement with the literature. ${ }^{11}$

( \pm )-trans-Dehydrodiferulate dimethyl ester (2)

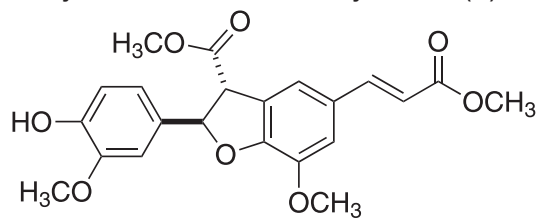

Yellow oil; IR (KBr pellet) $v_{\max } / \mathrm{cm}^{-1} 3395(-\mathrm{OH})$, $2951\left(\mathrm{C}_{\mathrm{sp}}{ }^{2}-\mathrm{H}\right), 1740(\mathrm{C}=\mathrm{O}), 1723(\mathrm{C}=\mathrm{O}), 1644(\mathrm{C}=\mathrm{C})$, $1594(\mathrm{C}=\mathrm{C}), 1523(\mathrm{C}=\mathrm{C}), 1432(\mathrm{C}=\mathrm{C}), 1269(\mathrm{C}-\mathrm{O})$, 1165 (C-O), 1140 (C-O), 1095 (C-O), 1036 (C-O), 982, 941, 853; ${ }^{1} \mathrm{H}$ NMR (400 MHz, acetone- $\left.d_{6}\right) \delta 7.63(1 \mathrm{H}, \mathrm{d}$, $J$ 16.1 Hz, H7'), 7.33 (1H, br s, H2'), 7.29 (1H, br s, H6'), $7.10(1 \mathrm{H}, \mathrm{d}, J 1.7 \mathrm{~Hz}, \mathrm{H} 2), 6.92$ (1H, dd, J 8.1, $1.7 \mathrm{~Hz}, \mathrm{H} 6)$, 6.84 (1H, d, J 8.1 Hz, H5), 6.44 (1H, d, J 16.1 Hz, H8'), 6.04 (1H, d, J 7.3 Hz, H7), 4.47 (1H, d, J 7.3 Hz, H8), 3.92 (3H, s, H11'), 3.84 (3H, s, H11'), 3.81 (3H, s, H10'), 3.73 $\left(3 \mathrm{H}, \mathrm{s}, \mathrm{H} 10\right.$ '); ${ }^{13} \mathrm{C} \mathrm{NMR}\left(100 \mathrm{MHz}\right.$, acetone- $\left.d_{6}\right) \delta 172.1(\mathrm{C}$, C9), 168.2 (C, C9'), 151.5 (C, C4'), 149.0 (C, C3), 148.5 (C, C4), 146.3 (C, C3'), 145.9 (CH, C7'), 132.5 (C, C1), 129.9 (C, C1'), 127.8 (C, C5'), 120.7 (CH, C6), $119.4(\mathrm{CH}$, C6'), 116.7 (CH, C8'), 116.3 (CH, C5), 113.9 (CH, C2'), 111.2 (CH, C2), 88.8 (CH, C7), $56.9\left(\mathrm{CH}_{3}, \mathrm{C} 11^{\prime}\right), 56.8$ $\left(\mathrm{CH}_{3}, \mathrm{C} 11^{\prime}\right), 56.4$ (CH, C8), $53.5\left(\mathrm{CH}_{3}, \mathrm{C} 10\right.$ '), $52.0\left(\mathrm{CH}_{3}\right.$, C10'); EI-MS (70 eV, $\mathrm{m} / \mathrm{z}$, relative intensity / \%): $\left.414 \mathrm{M}^{++}\right]$ (5), $382\left[\mathrm{M}^{++}-\mathrm{CH}_{3} \mathrm{OH}\right](90), 350\left[\mathrm{M}^{++}-\mathrm{CH}_{3} \mathrm{OH}-\mathrm{CH}_{3} \mathrm{OH}\right]$ (70). The NMR data are in agreement with the literature. ${ }^{11}$ 


\section{GC analyses}

The consumption of methyl esters I and II (i.e., conversion) and the formation of the DBNs 1 and 2 (i.e., selectivity) were monitored on a gas chromatograph GC-2010 Plus Shimadzu (Kyoto, Japan) fitted with a flame ionization detector (FID) detector and an RTX-5 fused silica capillary column $(30 \mathrm{~m} \times 0.25 \mathrm{~mm}$ i.d., $0.25-\mu \mathrm{m}$ film thickness). For this purpose, $20-\mu \mathrm{L}$ aliquots were sampled from the reaction mixture at pre-determined times $(1,2,3$, 4, and $20 \mathrm{~h}$ ) and transferred to a 1-mL Eppendorf plastic vial. The samples were filtered off to remove the oxidant; added to a $1-\mathrm{mL}$ vial containing $200 \mu \mathrm{L}$ of ethyl acetate for dilution; and injected into the gas chromatograph. The temperature was programmed to increase from 70 to $310^{\circ} \mathrm{C}$ at $15^{\circ} \mathrm{C} \mathrm{min}-1$ in $30 \mathrm{~min}$. The substances of interest were identified by comparison with retention times of standard samples.

\section{Results and Discussion}

\section{Optimization of the nature and concentration of the oxidant}

Although silver(I) oxide is the most commonly employed oxidant in the synthesis of dihydrobenzofuran neolignans via oxidative coupling of phenylpropanoids, different stoichiometries and reaction conditions have been reported. For instance, Lemière et al. ${ }^{18}$ used 1 equiv. of substrate $\mathbf{I I}$ and 0.5 equiv. of the oxidant $\left(\mathrm{Ag}_{2} \mathrm{O}\right)$ in a dry benzene/acetone $(5: 3 \mathrm{v} / \mathrm{v})$ mixture at room temperature for $20 \mathrm{~h}$, which afforded DBN 2 in $31 \%$ yield ([substrate] $=0.18 \mathrm{~mol} \mathrm{~L}^{-1}$; [oxidant] $\left.=0.09 \mathrm{~mol} \mathrm{~L}{ }^{-1}\right)$. Pieters et al. ${ }^{17}$ used 1 equiv. of substrate $\mathbf{I}$ and 0.7 equiv. of $\mathrm{Ag}_{2} \mathrm{O}$ in a dry benzene/ acetone $(7: 5 \mathrm{v} / \mathrm{v})$ mixture $\left([\right.$ substrate $]=0.23 \mathrm{~mol} \mathrm{~L}^{-1}$; [oxidant] $=0.16 \mathrm{~mol} \mathrm{~L}^{-1}$ ) at room temperature for $65 \mathrm{~h}$, to obtain DBN 1 in $23 \%$ yield. In turn, Orlandi et al. ${ }^{19}$ employed 1 equiv. of substrate II and 1.6 equiv. of $\mathrm{Ag}_{2} \mathrm{O}$ under inert atmosphere $\left(\mathrm{Ar}\right.$ or $\left.\mathrm{N}_{2}\right)$ in dry $\mathrm{CH}_{2} \mathrm{Cl}_{2}$ ([substrate $]=0.10 \mathrm{~mol} \mathrm{~L}^{-1}$; [oxidant $\left.]=0.16 \mathrm{~mol} \mathrm{~L}^{-1}\right)$ for 20-24 h at room temperature, which gave DBN 2 in $32 \%$ yield. Daquino et al. ${ }^{10}$ used 1 equiv. of methyl caffeate (substrate) and 1 equiv. of $\mathrm{Ag}_{2} \mathrm{O}$ in $\mathrm{CHCl}_{3}$ at room temperature for $2 \mathrm{~h}$, to obtain the corresponding DBN in $17.6 \%$ yield $\left([\right.$ substrate $]=[$ oxidant $\left.]=0.07 \mathrm{~mol} \mathrm{~L}^{-1}\right)$. Therefore, to date, there are no standard conditions regarding the use of silver(I) oxide as oxidant in the oxidative coupling of phenylpropanoids.

We started optimizing the oxidative coupling reaction conditions by investigating the oxidant. Sako et al. ${ }^{20}$ evaluated how different silver(I) reagents (e.g., AgOAc, $\mathrm{Ag}_{2} \mathrm{O}, \mathrm{Ag}_{2} \mathrm{CO}_{3}$, and $\mathrm{AgNO}_{3}$ ) affected the synthesis of the resveratrol dehydrodimer and obtained yields between 4 and $97 \%$. Thus, we decided to examine how the use of silver(I) reagents other than $\mathrm{Ag}_{2} \mathrm{O}$ impacted the oxidative coupling of methyl esters I and II. First, we employed 1 equiv. of methyl ester I or II $(0.56 \mathrm{mmol})$ and 1 equiv. of $\mathrm{Ag}^{+}$ions (0.56 mmol) dissolved in $2 \mathrm{~mL}$ of benzene/ acetone (6:4 v/v) under magnetic stirring. Besides $\mathrm{Ag}_{2} \mathrm{O}$ and $\mathrm{AgNO}_{3}$ (Merck, Darmstadt, Germany), which have already been reported ${ }^{20}$ as oxidants in this reaction, we also tested AgBr (Merck, Darmstadt, Germany), $\mathrm{AgOCOCF}_{3}$ (Aldrich, St. Louis, USA), and $\mathrm{AgOSO}_{2} \mathrm{CF}_{3}$ (Merck, Darmstadt, Germany). The conversion (C) and the selectivity (S) obtained from GC-FID analyses are shown in Tables 1 (methyl ester $\mathbf{I} \rightarrow \mathrm{DBN} \mathbf{1}$ ) and 2 (methyl ester $\mathbf{I I} \rightarrow$ DBN 2).

Under the same experimental conditions, methyl ferulate (II) conversion (i.e., the percentage of methyl ester that was consumed) was higher than methyl $p$-coumarate (I) conversion, regardless of the oxidant. On the other hand, selectivity (i.e., the percentage of methyl ester that was converted into the corresponding $\mathrm{DBN}$ ) was higher for methyl $p$-coumarate (I) as compared to methyl ferulate (II). This difference in the conversion of methyl esters I and II and in the selectivity toward DBNs $\mathbf{1}$ and $\mathbf{2}$, respectively, could explain, at least in principle, the lack of standard

Table 1. Methyl ester I (methyl $p$-coumarate) conversion (C) and selectivity (S) toward dihydrobenzofuran neolignan (DBN) $\mathbf{1}$ as a function of the silver(I) reagent, used as oxidant

\begin{tabular}{|c|c|c|c|c|c|c|c|c|c|c|}
\hline \multirow{2}{*}{$\begin{array}{l}0.56 \mathrm{mmol} \\
1 \text { equiv. } \mathrm{Ag}^{+} \\
\text {Reaction } \\
\text { time } / \mathrm{h}\end{array}$} & \multicolumn{2}{|c|}{$\begin{array}{c}\mathrm{Ag}_{2} \mathrm{O} \\
0.14 \mathrm{~mol} \mathrm{~L}^{-1}\end{array}$} & \multicolumn{2}{|c|}{$\begin{array}{c}\mathrm{AgNO}_{3} \\
0.28 \mathrm{~mol} \mathrm{~L}^{-1} \\
\end{array}$} & \multicolumn{2}{|c|}{$\begin{array}{c}\mathrm{AgBr} \\
0.28 \mathrm{~mol} \mathrm{~L}^{-1}\end{array}$} & \multicolumn{2}{|c|}{$\begin{array}{l}\mathrm{AgOCOCF}_{3} \\
0.28 \mathrm{~mol} \mathrm{~L}^{-1}\end{array}$} & \multicolumn{2}{|c|}{$\begin{array}{l}\mathrm{AgOSO}_{2} \mathrm{CF}_{3} \\
0.28 \mathrm{~mol} \mathrm{~L}^{-1}\end{array}$} \\
\hline & $\mathrm{C} / \%$ & $\mathrm{~S} / \%$ & $\mathrm{C} / \%$ & $\mathrm{~S} / \%$ & $\mathrm{C} / \%$ & $\mathrm{~S} / \%$ & $\mathrm{C} / \%$ & $\mathrm{~S} / \%$ & $\mathrm{C} / \%$ & $\mathrm{~S} / \%$ \\
\hline 1 & 9.8 & 61.7 & 1.0 & 5.0 & 0.8 & 3.8 & 11.8 & 88.3 & 2.1 & 6.5 \\
\hline 2 & 17.2 & 94.0 & 0.3 & 20.0 & 0.4 & 12.6 & 16.8 & 91.6 & 9.5 & 1.2 \\
\hline 3 & 24.8 & 82.0 & 0.4 & 14.0 & 0.2 & 55.0 & 20.3 & 83.3 & 13.2 & 11.8 \\
\hline 4 & 32.7 & 94.0 & 0.5 & 32.0 & 0.3 & 6.7 & 20.5 & 91.1 & 37.4 & 0.0 \\
\hline 20 & 35.3 & 66.4 & 1.4 & 22.9 & 1.5 & 7.1 & 20.0 & 78.2 & 5.7 & 2.8 \\
\hline
\end{tabular}


Table 2. Methyl ester II (methyl ferulate) conversion (C) and selectivity (S) toward dihydrobenzofuran neolignan (DBN) 2 as a function of the silver(I) reagent, used as oxidant

\begin{tabular}{|c|c|c|c|c|c|c|c|c|c|c|}
\hline \multirow{2}{*}{$\begin{array}{l}0.56 \mathrm{mmol} \\
1 \text { equiv. } \mathrm{Ag}^{+} \\
\text {Reaction } \\
\text { time } / \mathrm{h}\end{array}$} & \multicolumn{2}{|c|}{$\begin{array}{c}\mathrm{Ag}_{2} \mathrm{O} \\
0.14 \mathrm{~mol} \mathrm{~L}^{-1} \\
\end{array}$} & \multicolumn{2}{|c|}{$\begin{array}{c}\mathrm{AgNO}_{3} \\
0.28 \mathrm{~mol} \mathrm{~L}^{-1} \\
\end{array}$} & \multicolumn{2}{|c|}{$\begin{array}{c}\mathrm{AgBr} \\
0.28 \mathrm{~mol} \mathrm{~L}^{-1}\end{array}$} & \multicolumn{2}{|c|}{$\begin{array}{l}\mathrm{AgOCOCF}_{3} \\
0.28 \mathrm{~mol} \mathrm{~L}^{-1}\end{array}$} & \multicolumn{2}{|c|}{$\begin{array}{l}\mathrm{AgOSO}_{2} \mathrm{CF}_{3} \\
0.28 \mathrm{~mol} \mathrm{~L}^{-1} \\
\end{array}$} \\
\hline & $\mathrm{C} / \%$ & $\mathrm{~S} / \%$ & $\mathrm{C} / \%$ & $\mathrm{~S} / \%$ & $\mathrm{C} / \%$ & $\mathrm{~S} / \%$ & $\mathrm{C} / \%$ & $\mathrm{~S} / \%$ & $\mathrm{C} / \%$ & $\mathrm{~S} / \%$ \\
\hline 1 & 29.6 & 62.5 & 5.0 & 0.0 & 4.6 & 1.9 & 20.2 & 49.8 & 59.2 & 1.4 \\
\hline 2 & 52.9 & 85.0 & 4.0 & 5.8 & 4.4 & 3.7 & 25.8 & 61.9 & 75.1 & 1.4 \\
\hline 3 & 63.7 & 83.1 & 4.2 & 11.0 & 4.1 & 3.7 & 25.1 & 63.9 & 95.7 & 1.6 \\
\hline 4 & 67.7 & 85.8 & 4.3 & 10.8 & 4.4 & 2.3 & 26.3 & 62.8 & 99.9 & 0.0 \\
\hline 20 & 52.7 & 62.1 & 10.7 & 2.4 & 5.2 & 1.9 & 16.7 & 50.6 & 27.7 & 1.6 \\
\hline
\end{tabular}

conditions for the silver(I) oxide-promoted oxidative coupling reaction. However, we found that $\mathrm{Ag}_{2} \mathrm{O}$ was the most efficient oxidant because it provided the best balance between conversion and selectivity, especially for a reaction time of $4 \mathrm{~h}: 32.7 \%$ conversion of methyl ester I and $94.0 \%$ selectivity toward DBN $1 ; 67.7 \%$ conversion of methyl ester II and 85.8\% selectivity toward DBN 2. It is noteworthy that the use of $\mathrm{AgCO}_{2} \mathrm{CF}_{3}$ afforded good conversion and selectivity percentages even though these values were not as high as for $\mathrm{Ag}_{2} \mathrm{O}$.

In the literature, ${ }^{2,19} \mathrm{Ag}_{2} \mathrm{O}$ between 0.5 and 1.6 equiv. has been employed in the oxidative coupling of phenylpropanoids (oxidant concentrations ranging between 0.07 and $\left.0.16 \mathrm{~mol} \mathrm{~L}^{-1}\right)$. Here, we evaluated how different $\mathrm{Ag}_{2} \mathrm{O}$ concentrations affected the oxidative coupling of methyl esters I and II to produce DBNs $\mathbf{1}$ and 2 , respectively. To this end, we dissolved the methyl ester (1 equiv., $0.56 \mathrm{mmol})$ in a benzene/acetone $(6: 4 \mathrm{v} / \mathrm{v}$, $2 \mathrm{~mL}$ ) mixture and added the resulting solution to a round-bottom flask containing the oxidant and kept the reaction mixture under $\mathrm{N}_{2}$ atmosphere for $20 \mathrm{~h}$, covered with an aluminum foil. The oxidant impacted both the conversion and selectivity, as depicted in Tables 3 and 4 . Larger $\mathrm{Ag}_{2} \mathrm{O}$ amounts increased methyl ester conversion. On the other hand, larger $\mathrm{Ag}_{2} \mathrm{O}$ amounts also decreased selectivity, which indicated that side reactions probably occurred when larger $\mathrm{Ag}_{2} \mathrm{O}$ amounts were used. The best balance between conversion and selectivity was obtained for 0.5 equiv. of $\mathrm{Ag}_{2} \mathrm{O}$.

Table 3. Methyl ester I (methyl $p$-coumarate) conversion (C) and selectivity (S) toward dihydrobenzofuran neolignan (DBN) $\mathbf{1}$ as a function of the Ag $\mathrm{O}_{2} \mathrm{O}$ amount

\begin{tabular}{|c|c|c|c|c|c|c|c|c|}
\hline \multirow{2}{*}{$\begin{array}{l}\text { Reaction } \\
\text { time / h }\end{array}$} & \multicolumn{2}{|c|}{$\begin{array}{c}0.25 \text { equiv. } \\
0.035 \mathrm{~mol} \mathrm{~L}^{-1}\end{array}$} & \multicolumn{2}{|c|}{$\begin{array}{l}0.5 \text { equiv. } \\
0.07 \mathrm{~mol} \mathrm{~L}^{-1}\end{array}$} & \multicolumn{2}{|c|}{$\begin{array}{c}1 \text { equiv. } \\
0.14 \mathrm{~mol} \mathrm{~L}^{-1}\end{array}$} & \multicolumn{2}{|c|}{$\begin{array}{c}5 \text { equiv. } \\
0.70 \mathrm{~mol} \mathrm{~L}^{-1} \\
\end{array}$} \\
\hline & $\mathrm{C} / \%$ & $\mathrm{~S} / \%$ & $\mathrm{C} / \%$ & $\mathrm{~S} / \%$ & $\mathrm{C} / \%$ & $\mathrm{~S} / \%$ & $\mathrm{C} / \%$ & $\mathrm{~S} / \%$ \\
\hline 1 & 16.8 & 60.5 & 28.1 & 69.9 & 100.0 & 47.0 & 73.0 & 71.9 \\
\hline 2 & 22.4 & 74.0 & 67.5 & 70.5 & 87.8 & 66.0 & 83.0 & 61.2 \\
\hline 3 & 23.6 & 78.4 & 36.8 & 60.3 & 100.0 & 44.3 & 93.9 & 49.6 \\
\hline 4 & 24.0 & 73.2 & 34.3 & 69.7 & 98.7 & 25.7 & 100.0 & 70.0 \\
\hline 20 & 25.7 & 78.1 & 35.3 & 60.6 & 100.0 & 8.8 & 100.0 & 15.1 \\
\hline
\end{tabular}

Table 4. Methyl ester II (methyl ferulate) conversion (C) and selectivity (S) toward dihydrobenzofuran neolignan (DBN) 2 as a function of the $\mathrm{Ag}_{2} \mathrm{O}$ amount

\begin{tabular}{|c|c|c|c|c|c|c|c|c|}
\hline \multirow{2}{*}{$\begin{array}{l}\text { Reaction } \\
\text { time / h }\end{array}$} & \multicolumn{2}{|c|}{$\begin{array}{c}0.25 \text { equiv. } \\
0.035 \mathrm{~mol} \mathrm{~L}^{-1} \\
\end{array}$} & \multicolumn{2}{|c|}{$\begin{array}{c}0.5 \text { equiv. } \\
0.07 \mathrm{~mol} \mathrm{~L}^{-1}\end{array}$} & \multicolumn{2}{|c|}{$\begin{array}{c}1 \text { equiv. } \\
0.14 \mathrm{~mol} \mathrm{~L}^{-1}\end{array}$} & \multicolumn{2}{|c|}{$\begin{array}{c}5 \text { equiv. } \\
0.70 \mathrm{~mol} \mathrm{~L}^{-1}\end{array}$} \\
\hline & $\mathrm{C} / \%$ & $\mathrm{~S} / \%$ & $\mathrm{C} / \%$ & $\mathrm{~S} / \%$ & $\mathrm{C} / \%$ & $\mathrm{~S} / \%$ & $\mathrm{C} / \%$ & $\mathrm{~S} / \%$ \\
\hline 1 & 21.7 & 57.9 & 31.3 & 75.0 & 74.1 & 33.0 & 95.4 & 15.9 \\
\hline 2 & 25.0 & 55.4 & 39.4 & 66.3 & 44.8 & 43.2 & 93.8 & 16.0 \\
\hline 3 & 25.1 & 65.0 & 45.8 & 55.8 & 49.0 & 43.5 & 92.4 & 11.1 \\
\hline 4 & 28.6 & 53.6 & 44.4 & 63.1 & 95.1 & 25.6 & 97.7 & 20.8 \\
\hline 20 & 27.1 & 66.9 & 46.5 & 69.2 & 94.2 & 13.0 & 100.0 & 11.0 \\
\hline
\end{tabular}




\section{Optimization of the solvent}

Several solvents have been used in oxidative coupling reactions of phenylpropanoids. Dichloromethane and benzene/acetone and dichloromethane mixtures have been reported most often. Here, besides these two solvent systems, we also tested methanol and acetonitrile. The choice of these solvents was made on the basis of substrate solubility and the fact that methanol and acetonitrile are relatively "greener" as compared to other solvents: they present decreased toxicity and can be recycled for use in other reactions more times than other solvents. ${ }^{21}$ In these experiments, we dissolved 1 equiv. of the substrate (methyl ester I or II) in $2 \mathrm{~mL}$ of the tested solvent and added the resulting solution to a $10-\mathrm{mL}$ two-neck flask containing 0.5 equiv. of $\mathrm{Ag}_{2} \mathrm{O}$ or $\mathrm{AgCO}_{2} \mathrm{CF}_{3}$, the two best oxidant agents for this reaction. We covered the reaction vessel with aluminum foil and kept the reaction mixture under stirring and $\mathrm{N}_{2}$ atmosphere. The results are listed in Tables 5, 6, 7, and 8 .

In acetonitrile (Sigma-Aldrich, St. Louis, USA), the reactions proceeded with good yields and increased selectivity as compared to the other solvents. Silver(I) produces diverse complexes with weak coordinating ligands (e.g., halogens), besides being weakly oxophilic and forming numerous complexes with donor groups, such as $\mathrm{S}, \mathrm{Se}, \mathrm{P}, \mathrm{As}$, and $\mathrm{N}$ donor ligands. ${ }^{22}$ The increase in silver(I) valence due to formation of a complex when it is dissolved in cyanide solvents has been previously reported. ${ }^{23}$ In this sense, the increased selectivity and good conversion rate of the substrates obtained here suggested that acetonitrile, which is a good electron donor, can form highly stable complexes with silver(I) during the oxidation. Both oxidants provided higher selectivity toward the DBNs 1 and 2. Therefore, acetonitrile, which has not been previously reported as solvent for this reaction, is the best solvent to be used with $\mathrm{Ag}_{2} \mathrm{O}$, which in turn provides much more expressive results as compared to $\mathrm{AgCO}_{2} \mathrm{CF}_{3}$.

\section{Optimization of the temperature}

We also evaluated how the temperature influences the oxidative coupling of methyl esters I and II. Usually, these reactions are reported ${ }^{2,19}$ to occur at room temperature. However, Sako et al. ${ }^{20}$ obtained viniferin in $40 \%$ yield when they conducted AgOAc-promoted oxidative coupling in methanol under heating at $50{ }^{\circ} \mathrm{C}$ for $2 \mathrm{~h}$. Here, we investigated how three different temperatures $\left(0{ }^{\circ} \mathrm{C}\right.$, room temperature, and reflux at $85^{\circ} \mathrm{C}$ ) affected the oxidative coupling of methyl esters I and II by using $\operatorname{Ag}_{2} \mathrm{O}$, as oxidant, and acetonitrile, the best solvent for these reactions (Table 9).

Table 5. Methyl ester I (methyl p-coumarate) conversion (C) and selectivity (S) toward dihydrobenzofuran neolignan (DBN) 1 when Ag $\mathrm{O}_{2} \mathrm{O}(0.5$ equiv.) is used as oxidant in different solvents

\begin{tabular}{|c|c|c|c|c|c|c|c|c|}
\hline \multirow{2}{*}{$\begin{array}{l}\text { Reaction } \\
\text { time / h }\end{array}$} & \multicolumn{2}{|c|}{ DCM } & \multicolumn{2}{|c|}{ Benzene/acetone 6:4 (v/v) } & \multicolumn{2}{|c|}{$\mathrm{MeOH}$} & \multicolumn{2}{|c|}{$\mathrm{MeCN}$} \\
\hline & $\mathrm{C} / \%$ & $\mathrm{~S} / \%$ & $\mathrm{C} / \%$ & $\mathrm{~S} / \%$ & $\mathrm{C} / \%$ & $\mathrm{~S} / \%$ & $\mathrm{C} / \%$ & $\mathrm{~S} / \%$ \\
\hline 1 & 5.5 & 34.5 & 5.2 & 41.7 & 5.8 & 28.4 & 26.2 & 60.7 \\
\hline 2 & 7.1 & 50.4 & 10.0 & 55.5 & 8.6 & 36.6 & 35.0 & 62.7 \\
\hline 3 & 15.5 & 37.4 & 14.7 & 59.7 & 13.0 & 38.3 & 36.8 & 60.3 \\
\hline 4 & 15.3 & 63.8 & 12.7 & 57.2 & 12.7 & 43.7 & 34.3 & 69.6 \\
\hline 20 & 27.5 & 73.0 & 35.3 & 66.4 & 30.2 & 51.0 & 35.3 & 60.6 \\
\hline
\end{tabular}

DCM: dichloromethane; $\mathrm{MeOH}$ : methanol; $\mathrm{MeCN}$ : acetonitrile.

Table 6. Methyl ester II (methyl ferulate) conversion (C) and selectivity (S) toward dihydrobenzofuran neolignan (DBN) 2 when $\mathrm{Ag}_{2} \mathrm{O}(0.5$ equiv.) is used as oxidant in different solvents

\begin{tabular}{|c|c|c|c|c|c|c|c|c|}
\hline \multirow{2}{*}{$\begin{array}{l}\text { Reaction } \\
\text { time / h }\end{array}$} & \multicolumn{2}{|c|}{ DCM } & \multicolumn{2}{|c|}{ Benzene/acetone 6:4 (v/v) } & \multicolumn{2}{|c|}{$\mathrm{MeOH}$} & \multicolumn{2}{|c|}{$\mathrm{MeCN}$} \\
\hline & $\mathrm{C} / \%$ & $\mathrm{~S} / \%$ & $\mathrm{C} / \%$ & $\mathrm{~S} / \%$ & $\mathrm{C} / \%$ & $\mathrm{~S} / \%$ & $\mathrm{C} / \%$ & $\mathrm{~S} / \%$ \\
\hline 1 & 19.1 & 71.6 & 24.2 & 65.0 & 30.6 & 56.0 & 18.6 & 71.1 \\
\hline 2 & 40.1 & 44.4 & 27.6 & 62.4 & 44.6 & 55.0 & 32.6 & 69.6 \\
\hline 3 & 45.1 & 37.6 & 33.0 & 61.3 & 49.6 & 46.0 & 37.0 & 64.9 \\
\hline 4 & 44.7 & 38.5 & 31.8 & 58.1 & 54.7 & 41.7 & 39.1 & 69.1 \\
\hline 20 & 49.5 & 37.1 & 38.6 & 53.3 & 60.5 & 11.9 & 45.0 & 67.5 \\
\hline
\end{tabular}

DCM: dichloromethane; MeOH: methanol; MeCN: acetonitrile. 
Table 7. Methyl ester I (methyl p-coumarate) conversion (C) and selectivity (S) toward dihydrobenzofuran neolignan (DBN) $\mathbf{1}$ when $\mathrm{AgCO}_{2} \mathrm{CF}_{3}(0.5$ equiv.) is used as oxidant in different solvents

\begin{tabular}{|c|c|c|c|c|c|c|c|c|}
\hline \multirow{2}{*}{$\begin{array}{l}\text { Reaction } \\
\text { time / h }\end{array}$} & \multicolumn{2}{|c|}{ DCM } & \multicolumn{2}{|c|}{ Benzene/acetone $6: 4(\mathrm{v} / \mathrm{v})$} & \multicolumn{2}{|c|}{$\mathrm{MeOH}$} & \multicolumn{2}{|c|}{$\mathrm{MeCN}$} \\
\hline & $\mathrm{C} / \%$ & $\mathrm{~S} / \%$ & $\mathrm{C} / \%$ & $\mathrm{~S} / \%$ & $\mathrm{C} / \%$ & $\mathrm{~S} / \%$ & $\mathrm{C} / \%$ & $\mathrm{~S} / \%$ \\
\hline 1 & 3.6 & 30.6 & 8.1 & 50.8 & 4.4 & 46.9 & 7.7 & 52.1 \\
\hline 2 & 7.5 & 45.4 & 10.5 & 55.3 & 9.6 & 63.6 & 4.7 & 56.6 \\
\hline 3 & 6.2 & 14.7 & 10.3 & 57.2 & 8.6 & 61.7 & 8.4 & 72.8 \\
\hline 4 & 9.0 & 45.1 & 10.6 & 53.8 & 10.2 & 70.9 & 11.6 & 72.6 \\
\hline 20 & 3.9 & 48.5 & 10.3 & 55.8 & 9.2 & 65.8 & 10.4 & 65.9 \\
\hline
\end{tabular}

DCM: dichloromethane; MeOH: methanol; MeCN: acetonitrile.

Table 8. Methyl ester II (methyl ferulate) conversion (C) and selectivity (S) toward dihydrobenzofuran neolignan (DBN) 2 when $\mathrm{AgCO}_{2} \mathrm{CF}_{3}(0.5$ equiv.) is used as oxidant in different solvents

\begin{tabular}{|c|c|c|c|c|c|c|c|c|}
\hline \multirow{2}{*}{$\begin{array}{l}\text { Reaction } \\
\text { time / h }\end{array}$} & \multicolumn{2}{|c|}{ DCM } & \multicolumn{2}{|c|}{ Benzene/acetone $6: 4(\mathrm{v} / \mathrm{v})$} & \multicolumn{2}{|c|}{$\mathrm{MeOH}$} & \multicolumn{2}{|c|}{$\mathrm{MeCN}$} \\
\hline & $\mathrm{C} / \%$ & $\mathrm{~S} / \%$ & $\mathrm{C} / \%$ & $\mathrm{~S} / \%$ & $\mathrm{C} / \%$ & $\mathrm{~S} / \%$ & $\mathrm{C} / \%$ & $\mathrm{~S} / \%$ \\
\hline 1 & 1.8 & 13.2 & 13.9 & 51.2 & 15.0 & 56.5 & 18.9 & 70.2 \\
\hline 2 & 4.5 & 23.2 & 13.6 & 49.4 & 15.8 & 56.2 & 14.7 & 61.4 \\
\hline 3 & 6.8 & 27.8 & 22.8 & 42.5 & 20.2 & 46.5 & 17.2 & 59.7 \\
\hline 4 & 7.0 & 30.0 & 15.3 & 37.6 & 16.2 & 35.3 & 17.2 & 55.6 \\
\hline 20 & 24.0 & 43.1 & 15.9 & 41.6 & 30.2 & 29.7 & 7.9 & 48.0 \\
\hline
\end{tabular}

DCM: dichloromethane; $\mathrm{MeOH}$ : methanol; $\mathrm{MeCN}$ : acetonitrile.

Table 9. Methyl ester I (methyl p-coumarate) and methyl ester II (methyl ferulate) conversion (C) and selectivity (S) toward dihydrobenzofuran neolignans (DBN) 1 and 2, respectively, when $\mathrm{Ag}_{2} \mathrm{O}$ ( 0.5 equiv.) was used as oxidant in acetonitrile at different temperatures

\begin{tabular}{|c|c|c|c|c|c|c|c|c|c|c|c|c|}
\hline \multirow{3}{*}{$\begin{array}{l}\text { Reaction } \\
\text { time / h }\end{array}$} & \multicolumn{4}{|c|}{ Room temperature } & \multicolumn{4}{|c|}{$0{ }^{\circ} \mathrm{C}$} & \multicolumn{4}{|c|}{ Reflux } \\
\hline & \multicolumn{2}{|c|}{$\mathbf{I}$} & \multicolumn{2}{|c|}{ II } & \multicolumn{2}{|c|}{ I } & \multicolumn{2}{|c|}{ II } & \multicolumn{2}{|c|}{ I } & \multicolumn{2}{|c|}{ II } \\
\hline & $\mathrm{C} / \%$ & $\mathrm{~S} / \%$ & $\mathrm{C} / \%$ & $\mathrm{~S} / \%$ & $\mathrm{C} / \%$ & $\mathrm{~S} / \%$ & $\mathrm{C} / \%$ & $\mathrm{~S} / \%$ & $\mathrm{C} / \%$ & $\mathrm{~S} / \%$ & $\mathrm{C} / \%$ & $\mathrm{~S} / \%$ \\
\hline 1 & 49.7 & 76.3 & 29.8 & 76.0 & 6.6 & 31.0 & 12.9 & 61.3 & 28.6 & 73.7 & 63.7 & 78.3 \\
\hline 2 & 47.6 & 72.7 & 39.0 & 76.6 & 6.9 & 23.8 & 18.9 & 67.9 & 29.8 & 66.1 & 68.8 & 58.8 \\
\hline 3 & 57.1 & 73.2 & 38.6 & 78.4 & 9.8 & 44.5 & 23.1 & 71.4 & 26.9 & 63.1 & 66.3 & 74.3 \\
\hline 4 & 50.1 & 75.3 & 41.7 & 77.1 & 11.9 & 50.0 & 35.5 & 77.3 & 30.0 & 56.3 & 65.7 & 71.0 \\
\hline 20 & 49.1 & 71.7 & 45.4 & 77.3 & 44.9 & 71.1 & 46.9 & 71.3 & 44.4 & 42.1 & 68.0 & 64.1 \\
\hline
\end{tabular}

Both conversion and selectivity decreased at $0{ }^{\circ} \mathrm{C}$ for both methyl esters. On the other hand, reflux conditions provided better homogenization of the reaction mixture and gave good selectivity and conversion. However, reaction time of $20 \mathrm{~h}$ decreased selectivity probably because side reactions took place, to afford products other than the DBNs 1 and 2.

\section{Optimization of the reaction time}

Pieters et al. ${ }^{17}$ reported that the optimum time for the silver(I)-promoted oxidative coupling of methyl esters I and
II and analogs is $20 \mathrm{~h}$. Nevertheless, our results revealed that this time could be optimized to $4 \mathrm{~h}$ in acetonitrile and 0.5 equiv. of $\mathrm{Ag}_{2} \mathrm{O}$ without decreasing conversion and selectivity. The disadvantages of longer reaction times include reduced selectivity due to formation of undesired products.

The reflux condition was the most efficient among the tested conditions, especially in the case of methyl ester II (Table 9). However, we selected room temperature as the most adequate temperature for this reaction because it requires less energy and provides higher selectivity than reflux conditions. 
Table 10. Methyl ester I (methyl p-coumarate) and methyl ester II (methyl ferulate) conversion (C) and selectivity (S) toward dihydrobenzofuran neolignans (DBN) 1 and 2, respectively, when $\mathrm{Ag}_{2} \mathrm{O}$ ( 0.5 equiv., as oxidant) in acetonitrile at room temperature was used together with AIBN (radical initiator) or isoquinoline (radical inhibitor)

\begin{tabular}{|c|c|c|c|c|c|c|c|c|}
\hline \multirow{3}{*}{$\begin{array}{l}\text { Reaction } \\
\text { time / h }\end{array}$} & \multicolumn{4}{|c|}{ AIBN } & \multicolumn{4}{|c|}{ Isoquinoline } \\
\hline & \multicolumn{2}{|c|}{ I } & \multicolumn{2}{|c|}{ II } & \multicolumn{2}{|c|}{ I } & \multicolumn{2}{|c|}{ II } \\
\hline & $\mathrm{C} / \%$ & $\mathrm{~S} / \%$ & $\mathrm{C} / \%$ & $\mathrm{~S} / \%$ & $\mathrm{C} / \%$ & $\mathrm{~S} / \%$ & $\mathrm{C} / \%$ & $\mathrm{~S} / \%$ \\
\hline 1 & 80.0 & 5.7 & 70.2 & 7.1 & 57.9 & 49.1 & 38.1 & 35.0 \\
\hline 2 & 87.6 & 5.8 & 73.8 & 8.2 & 60.1 & 46.5 & 45.6 & 41.2 \\
\hline 3 & 85.8 & 6.1 & 76.9 & 7.0 & 60.5 & 47.7 & 43.7 & 41.5 \\
\hline 4 & 88.8 & 5.6 & 78.3 & 6.4 & 60.2 & 45.7 & 47.8 & 39.0 \\
\hline 20 & 86.3 & 5.6 & 78.6 & 10.1 & 62.5 & 47.1 & 48.6 & 40.1 \\
\hline
\end{tabular}

AIBN: azobisisobutyronitrile.

Effect of radical initiator and inhibitor

AIBN (azobisisobutyronitrile) is a radical initiator due to its decomposition into 1-cyanoprop-1-yl radical, which is driven by $\mathrm{N}_{2}$ elimination (Scheme 3 ). ${ }^{24} \mathrm{AIBN}$ has been used in many reactions in which radical intermediate species are involved. ${ }^{25}$ Because the mechanism proposed in the literature ${ }^{10,26}$ for the silver(I)-oxide oxidative coupling of phenylpropanoids involves the formation of radical intermediate species (Scheme 1), we decided to investigate how AIBN affected the synthesis of DBNs 1 and $\mathbf{2}$ from methyl esters I and II, respectively (Table 10). AIBN significantly increased methyl ester conversion in all the reaction times as compared to the reaction conducted under the same experimental conditions without AIBN addition. However, the selectivity toward DBNs 1 and $\mathbf{2}$ decreased drastically. This data indicated that AIBN addition to the reaction mixture generated other radical species that resulted in the formation of products other than the DBNs 1 and $\mathbf{2}$ even when the optimized conditions for oxidant, solvent, temperature, and reaction time were employed.

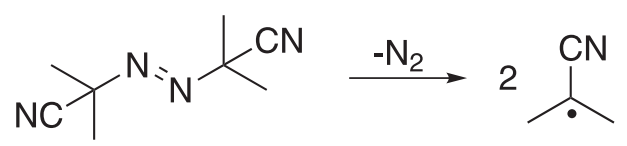

Scheme 3. Mechanism of 1-cyanoisoprop-1-yl radical formation from AIBN (adapted from reference 24).

Finally, we decided to verify how isoquinoline impacted the synthesis of DBNs $\mathbf{1}$ and $\mathbf{2}$ from methyl esters I and II, respectively. Isoquinoline acts as a radical inhibitor in organic synthesis. ${ }^{27}$ Because the silver(I) oxide-promoted oxidative coupling of methyl esters I and II to produce $\mathbf{1}$ and $\mathbf{2}$, respectively, has been suggested to involve intermediate radical species, we expected that isoquinoline addition would decrease the conversion of methyl esters I and II and the selectivity toward DBNs $\mathbf{1}$ and $\mathbf{2}$, respectively. Surprisingly, although the selectivity decreased, the conversion of methyl esters I and II increased when isoquinoline was added. These results did not clarify the involvement of radical intermediate species in this reaction.

\section{Conclusions}

Silver(I) oxide ( 0.5 equiv.) is the most efficient oxidant amongst the silver(I) reagents that we tested to promote the oxidative coupling of methyl $p$-coumarate (I) and methyl ferulate (II) to produce the dihydrobenzofuran neolignans $\mathbf{1}$ and $\mathbf{2}$. Acetonitrile, which has not been previously reported as solvent for this reaction, affords the best balance between conversion and selectivity, besides being "greener" than other more frequently employed solvents (e.g., dichloromethane and benzene). Under the optimized conditions, the reaction time can be reduced from 20 to $4 \mathrm{~h}$ without a significant decrease in conversion and selectivity. AIBN (a radical initiator) addition increases conversion and decreases selectivity, whereas isoquinoline (a radical inhibitor) addition slightly decreases reactivity and increases selectivity. The results of the experiments involving radical inhibitors/initiators to prove the involvement of radical intermediate species in the silver(I)-promoted oxidative coupling of the methyl esters I and II are not conclusive and must be investigated by other correlated experiments (e.g., mass spectrometry).

\section{Supplementary Information}

Supplementary information (IR, ${ }^{1} \mathrm{H}$ and ${ }^{13} \mathrm{C}$ NMR, and EI-MS spectra) is available free of charge at http://jbcs.sbq.org.br as PDF file. 


\section{Acknowledgments}

The authors thank the Brazilian Foundations FAPESP (process 2013/20094-0) and CNPq for fellowships and grants.

\section{References}

1. Moss, G. P.; Pure Appl. Chem. 2000, 72, 1493.

2. Dias, H. J.; Silva, E. O.; Vieira, T. M.; Crotti, A. E. M. In Benzofuran: Production and Applications; Barros, M. S., ed.; Nova Science Publisher: Hauppauge, NY, 2020.

3. Liu, Q.-B.; Huang, X.-X.; Bai, M.; Chang, X.-B.; Yan, X.-J.; Zhu, T.; Zhao, W.; Peng, Y.; Song, S.-J.; J. Agric. Food Chem. 2014, 62, 7796.

4. Fukui, M. J.; Dias, H. J.; Severiano, M. E.; de Souza, M. G. M.; de Oliveira, P. F.; Ambrósio, S. R.; Martins, C. H. G.; Tavares, D. C.; Crotti, A. E. M.; ChemistrySelect 2018, 3, 1836.

5. Dias, H. J.; Patrocínio, A. B.; Pagotti, M. C.; Fukui, M. J.; Rodrigues, V.; Magalhães, L. G.; Crotti, A. E. M.; Chem. Biodiversity 2018, 15, e1800134.

6. Van Miert, S.; Dyck, S. V.; Schmidt, T. J.; Brun, R.; Vlietinck, A.; Lemière, G.; Pieters, L.; Bioorg. Med. Chem. 2005, 13, 661.

7. Baldin, E. L. L.; Dias, H. J.; de Souza, C. M.; Soares, M. C. E.; Grundman, C. O.; Santos, T. L. B.; Crotti, A. E. M.; J. Pest Sci. 2019, 92, 861.

8. Garcia-Muñoz, S.; Alvarez-Corral, M.; Jimenez-Gonzalez, L.; Lopez-Sanchez, C.; Rosales, A.; Muñoz-Dorado, M.; Rodriguez-Garcia, I.; Tetrahedron 2006, 62, 12182.

9. Hemelaere, R.; Carreaux, F.; Carboni, B.; Eur. J. Org. Chem. 2015, 2015, 2470.

10. Daquino, C.; Rescifina, A.; Spatafora, C.; Tringali, C.; Eur. J. Org. Chem. 2009, 2009, 6289.

11. Medeiros, T. C. T.; Dias, H. J.; Silva, E. O.; Fukui, M. J.; Soares, A. C. F.; Kar, T.; Heleno, V. C. G.; Donate, P. M.; Parreira, R. L. T.; Crotti, A. E. M.; J. Braz. Chem. Soc. 2016, 27, 136.

12. Kuo, Y.-H.; Wu, C.-H.; J. Nat. Prod. 1996, 59, 625.

13. Blum, T. R.; Zhu, Y.; Nordeen, S. A.; Yoon, T. P.; Angew. Chem. 2014, 53, 11056.
14. Chioccara, F.; Poli, S.; Rindone, B.; Pilati, T.; Brunow, G.; Pietikäinen, P.; Setälä, H.; Tsuda, T.; Acta Chem. Scand. 1993, 47, 610; Yoshihara, T.; Yamaguchi, K.; Sakamura, S.; Agric. Biol. Chem. 1983, 47, 217.

15. Erdtman, H.; Justus Liebigs Ann. Chem. 1933, 503, 283.

16. Dias, H. J.; Baguenard, M.; Crevelin, E. J.; Palaretti, V.; Gates, P. J.; Vessecchi, R.; Crotti, A. E. M.; J. Mass Spectrom. 2019, $54,35$.

17. Pieters, L.; Van Dyck, S.; Gao, M.; Bai, R.; Hamel, E.; Vlietinck, A.; Lemiere, G.; J. Med. Chem. 1999, 42, 5475.

18. Lemière, G.; Gao, M.; de Groot, A.; Dommisse, R.; Lepoivre, J.; Pieters, L.; Buss, V.; J. Chem. Soc., Perkin Trans. 1 1995, 1775 .

19. Orlandi, M.; Rindone, B.; Molteni, G.; Rummakko, P.; Brunow, G.; Tetrahedron 2001, 57, 371.

20. Sako, M.; Hosokawa, H.; Ito, T.; Iinuma, M.; J. Org. Chem. 2004, 69, 2598.

21. Anastas, P. T.; Warner, J. C.; Green Chemistry: Theory and Practice; Oxford University Press: New York, NY, 1998.

22. Dance, I. J.; Polyhedron 1986, 1986, 1037; Blower, P. J.; Dilworth, J. R.; Coord. Rev. Chem. 1987, 76, 121.

23. Gimeno, M. C.; Laguna, A.; Meyer, T. J.; Comprehensive Coordination Chemistry II; Pergamon: Oxford, 2003.

24. Krstina, J.; Moad, G.; Willing, R. I.; Danek, S. K.; Kelly, D. P.; Jones, S. L.; Solomon, D. H.; Eur. Polym. J. 1993, 29, 379.

25. Bloger, D. L.; Mathvink, R. J.; J. Org. Chem. 1992, 57, 1429; Chatgilialoglu, C.; Ferreri, C.; Ballestri, M.; Curran, D. P.; Tetrahedron Lett. 1996, 37, 6387; Beaufils, F.; Denes, F.; Renaud, P.; Org. Lett. 2004, 6, 2563.

26. Quideuau, S.; Ralph, J.; Holzforshung 1994, 48, 12; Maeda, S.; Masuda, H.; Tokoroyama, T.; Chem. Pharm. Bull. 1995, 43, 935.

27. Minisci, F.; Zhao, L.; Fontana, F.; Bravo, A.; Tetrahedron Lett. 1995, 36, 1895; Jang, M. H.; Kim, H. Y.; Kang, K. S.; Yokozawa, T.; Park, J. H.; Arch. Pharm. Res. 2009, 32, 341; Bernotas, R. C.; Thomas, C. E.; Carr, A. A.; Nieduzak, T. R.; Adams, G.; Ohlweiler, D. F.; Hay, D. A.; Bioorg. Med. Chem. Lett. 1996, 6,1105 . 